\title{
R. Wittkower y el palladianismo inglés
}

\author{
Ramón Rodríguez Llega *
}

\begin{abstract}
RESUMEN
ABSTRACT

No existen apenas aproximaciones a la figura de $R$. Wittkower (1901-1971) en la historiografia de la arquitectura escrita en español. Sin embargo, se han traducido la mayor parte de sus textos importantes, aunque alguno de manera incompleta, como es el caso de "Palladio and English Palladianism". Bajo este título, en realidad una recopilación de textos que tienen a Palladio como común denominador, el autor rinde homenaje intelectual a Inglaterra, su segunda

patria de adopción, dado que era berlinés de nacimiento.

La formación juvenil de $R$. Wittkower tiene como marco de referenciaa esta ciudad, tambien el eco de la llamada Escuela de Viena (Dvorak, Hempel,

Frey, Cassirer o Panofsky), $y$, en tercer lugar, la indispensable estancia

en Roma, lugar de encuentros y apasionados estudios y debates. El

There isn't almost any approximation to the figure of $R$. Wittkower (1901-1971) in history of architecture written in Spanish. However, most of his important texts have been translated, although incompletely, like the case of "Palladio and English Palladianism». Under this title, wich is in fact a summary of texts with Palladio as a common name, the author pays homage to England, his second adoption native land, because he was born in Belin.

$R$. Wittkower's young formation has got this city as a frame, also the eco of one called School of Vienna (Dvorak, Hempel, Frey, Cassirer or Panofsky), and thirdly, his indispensable statement in Rome, place of meetings and excitings studies and debates. Young Wittkower, from the privileged tower of Hertziana Library, confront himself with the bigest authors $(H$.
\end{abstract}

* Profesor de Historia de la Arquitectura. E.T.S. Arquitectura. Universidad de Valladolid. 
joven Wittkower, desde la atalaya privilegiada de la Biblioteca Hertziana,

se confronta pronto con los grandes (H. Seldmayr), y se compromete con futuros temas que le darán fama $y$ prestigio (Bernini escultor, Miguel

Angel, Arte y Arquitectura del Renacimiento y Barroco italiano...). Entre 1934 y 1956 acaece el llamado "periodo inglés» de R. Wittkower,

huyendo del ambiente nazi que oprimía a la hasta entonces sobresaliente cultura centroeuropea.

El "Journal of the Warburg and Courtauld Institutes" será el medio de exposición de los trabajos de tantos exiliados, tambien donde apararezcan los destacados estudios de $R$.

Wittkower sobre Alberti y Palladio,

base de sus importantes obras posteriores, "Architectural Principles

in the Age of Humanism"(1949) en especial.

Nuestro artículo se detiene particularmente en este momento de los estudios de R. Wittkower, con su deseo de búsqueda de estructuras racionales en la historia, sin renunciar a la implicación contemporánea e interesada de ello mismo. En este sentido, le resulta enormemente útil la figura de Palladio y sus "migraciones" al contexto arquitectónico inglés, un paralelo con otras migraciones artísticas en la historia, con la forzada suya propia.

A partir de 1956, R. Wittkower se incorpora a la Columbia University de

Nueva York, y alli permanece hasta su jubilación en 1969, época en la que ve reconocido el fruto de su trabajo y

a la que pertenecen algunas de sus obras más divulgadas, como "Art and

Architecture in Italy 1600-1750, (1958), o «Born under Saturn" (1963).
Seldmayrs), and he compromises with future topics those will bring him fame and prestige (Bernini as sculptor, Michelangelo, Art and Architecture in Renaissance and italian Baroque...). Between 1934 and 1956 the one called "english period" of $R$. Wittkower happens, escaping from nazi ambient wich oppressed at the outstanding till there Central European culture. The "Journal of the Warburg and Courtauld Institutes" will be the way of expotition of many exile's works, and also where the most important studies of $R$. Wittkower about Alberti and Palladio will appear, it will be the basement of his later pieces of work, specialy "Architectural Principles in the Age of Humanism》 (1949).

Our article stops particulary in this moment of $R$. Wittkower's studies, with the wish of a search of rational structures in history, without renounce to the contemporary commitment and interested in this one. In this sense, it is really useful the figure of Palladio and his "migrations" to the english architectural context, wich is a parallel with other artistic migrations in history, with his forced ownone. 
Salvo la ya lejana introducción de Ángel González al texto publicado en la editorial G. Gili en 1979, no conozco ningún otro estudio español que se haya acercado a la figura y personalidad intelectual de R. Wittkower (19011971) salvo para referenciarla parcialmente, o con intereses muy ceñidos, como ocurre con la versión breve que nos brinda más recientemente J. A. Ramírez ${ }^{1}$. Sus textos han sido traducidos demasiado aleatoriamente, aunque sí estan presentes sus libros más decisivos. Quizá debido a su propio interés centrado en la arquitectura histórica, particularmente la renacentista y barroca, esto mismo le haya sustraído del campo más asiduo a la especulación teórica y ensayística, el de los historiadores del arte, en tanto que los arquitectos, quienes más de cerca hubieran debido seguir su estela, se dedican normalmente a otros asuntos. De modo que reaparece así la edición tan deseada de "Los fundamentos de la arquitectura en la edad del humanismo" - Madrid 1995-, originaria de 1949 en la versión inglesa y conocedora de una edición en español por parte de la editorial Nueva Visión -Buenos Aires 1958- y lo hace sin ningún estudio crítico acompañante y sólo una escueta "Nota del Editor" introductoria lo salva del desamparo total.

Sin embargo hay un halo de admiración que no cesa hacia la figura de R. Wittkower, su pensamiento goza aún de demanda necesaria, aunque en España se le hayan hurtado pasajes significativos de su producción intelectual, como ocurrió con la publicación del libro aquí titulado "Sobre la arquitectura en la edad del humanismo. Ensayos críticos» (G. Gili, Barcelona 1979), dado que en él, entonces, aparecieron traducidos tres de los textos — «Palladio y Bernini», «Inigo Jones, arquitecto y hombre de letras» $y$ "Lord Burlington y William Kent"- que formaban parte, a su vez, de los trece en total que en su día se editaron póstumamente con el título genérico de «Palladio and English Palladianism» -1974- bajo la supervisión de su viuda, Margot Wittkower. Quizá el "nacionalismo" presupuesto bajo el título haya sido causa probable de no haberse acometido la presentación global de la obra, aunque sí se haya vertido, lógicamente, al italiano. Pero puede más en definitiva el peso de la pena por esta carencia que cualquier otra justificación, por forzada e incierta que sea. (El resto de los textos no publicados en la edición española versaban sobre los siguientes asuntos:"La influencia de Palladio en el desarrollo de la arquitectura religiosa veneciana en el Seis y Setecientos"; "Palladio y el balaustre renacentista»; "Inigo Jones, puritano orgulloso»; "El neoclasicismo

AAVV: “Historia de las ideas estéticas y de las teorías artísticas contemporáneas. Iconografía e Iconología”. Edit. La Balsa de la Medusa. Madrid 1996, Vol. II, pág. 241. 
inglés y las vicisitudes de los Quattro Libri de Palladio"; "La literatura inglesa de arquitectura"; "La obra de Lord Burlington en York"; "Lord Burlington en Northwick Park»; "Elementos pseudopalladianos en el neoclasicismo inglés"; "El neopalladianismo inglés, el jardín paisajistico, China y la llustración»; "Teoria clásica y sensibilidad en el Setecientos").

Aunque bajo el citado título pueda reconocerse un afán por parte de $\mathrm{R}$. Wittkower de devolver su agradecimiento al país paterno en el que residió desde 1934 hasta su marcha a la Universidad de Columbia en 1956, nada más lejos del autor que las miras intelectuales estrechas o localistas: toda su trayectoria personal y académica fue un permanente gesto demostrando la militancia y pertenencia al ámbito del cosmopolitismo, de lo universal.

Rudolph Wittkower nació en Berlín en 1901, y siendo su linaje de raíz judía, parece como si esta condición le afectara en que su vida se verá abocada a un éxodo permanente. Los estudios berlineses juveniles culminan en 1923, doctorándose con un trabajo sobre la pintura del «quattrocento» en Verona, dirigida por el historiador Goldschmidt. La primera estancia exterior la efectuará entre 1923 y 1932 como asistente en la biblioteca Herztziana de Roma, etapa fundamental en su formación, en la que elige el que será su campo preferente de estudios y aportaciones futuras: el renacimiento y barroco italianos y, en concreto, dos de sus figuras señeras, Miguel Angel y Bernini, a las que posteriormente se incorporará Palladio.

Los trabajos y publicaciones primeras de R.Wittkower consisten básicamente en completar y organizar la documentación y bibliografía sobre dichos artistas, partiendo en el caso de Miguel Angel de la ingente tarea previa de Tolnay. Este aspecto de energía e inteligencia organizadora acompañará siempre al talante de Wittkower, sin que ello le impida elevar las miras hacia el espacio de la reflexión genérica y la búsqueda de principios básicos del arte. Es más, este carácter minucioso de atender al dato, que tiene su correlato en la atención pormenorizada y analítica de la obra singular, le supondrá pronto enfrentamientos con la comunidad científica de los años treinta, siendo bien conocido el episodio de sus desencuentros con H. Sedlmayr, quien se autoproclamaba ya en 1930 como el legítimo heredero de la afamada Escuela de Viena, formada, entre otros, por Dvorák, Hempel, Frey, Cassirer y Panofsky ${ }^{2}$. La ocasión del enfrentamiento entre ambos partió de la recensión de Sedlmayr a la obra de Coudenhore-Ertal sobre Carlo Fontana, a la que el historiador vienés conside-

Marco PogacNIK: "Introduzione", de la obra de H. Sedlmayr "L'architettura di Borromini». Edit. Electa, Milano 1996. 
ra puramente documental, propia del rango de lo que él llamaba la «primera historia del arte», excluyendo la comprensión e interpretación de la obra, propia de una fase posterior y de superior rango, a la que Sedlmayr calificaba como "segunda historiografía", siendo la historiografía ideal el resultado de la cooperación de ambos dos niveles. Wittkower lo que achaca en su crítica a la obra es su carácter "precipitado", pues no era posible afrontar la obra de Carlo Fontana sin investigar previamente a los arquitectos del barroco inicial como Maderno, Longhi y Cortona, y, además, de no haber tomado en consideración el material original conservado en la biblioteca Windsor en veintisiete voluminosos tomos.

La respuesta de Sedimayr a Wittkower consituye todo otro asunto que nos llevaría al terreno específico del no menos destacado estudioso vienés, quien confiaba más en sus ejercicios de análisis estructural y del poder de la visión en el acercamiento a las obras de arte, pues su reclamo permanente frente al formalismo inicial de Wittkower es precisamente la crítica por el abandono de los estudios específicos de la historia del arte, la gran aportación de la llamada "escuela de Viena» y, en particular, de sus brillantes análisis estilísticos, en definitiva los estudios que reconducían de nuevo a la figura de $\mathrm{A}$. Riegl.

El joven Wittkower, desde la privilegiada atalaya de la biblioteca Hertziana, se confronta pronto con los grandes, va comprometiéndose con futuros temas que le darán fama y prestigio (“Bernini escultor», por ejemplo, en colaboración con Brauer, en 1931, posteriormente publicado en 1955) base de un género, la biografía, que Wittkower tomará como algo propio y que culminará en la obra de 1963 escrita en colaboración con su mujer, Margot, "Nacidos bajo el signo de Saturno", y allí, entonces todavía, el autor reclamará, pese a las sugerencias y aperturas del tema, que las ideas desarrolladas derivan de los documentos "discriminados", no de ideas preconcebidas, aunque la madurez y la autoridad adquirida ya entonces le permita confesar que «buscábamos la lectura fluida antes que la perfección filológica» (de la edición española, edit. Cátedra, Madrid 1982).

La culminación de los estudios italianos de Wittkower será su obra «Arte y arquitectura en Italia 1600-1750", pertenenciente a la colección Pelikan de Historia del Arte, dirigida por su amigo N. Pevsner. En ella el ingente material y la inteligencia crítica encuentran perfecto acomodo.La conciencia metodológica le lleva a expresar las intenciones con claridad en el Prólogo, justificando presencias y ausencias y proporciones de los tratamientos, aunque se muestra dispuesto a aceptar el reto y el significado de su elección: "Las ideas nuevas y fértiles han sido siempre escasísimas. Es el origen, divulgación y expansión de estas ideas lo que a mí me 
interesa. Su eco y su transformación en la obra de los artistas de segunda fila pueden ser esbozados con una gran pincelada (...) Mi propósito es más limitado pero quizá más ambicioso. En lugar de decir poco de muchas cosas, intento decir algo sobre unas cuantas" (de la edición española, edit. Cátedra, Madrid 1979).

Resulta éste así un siempre dificil libro de síntesis con el cual el autor trata y consigue devolverle la dignidad perdida a la Italia barroca, aportando para ello un sistema deudor de su propia experiencia como docente y de todos sus estudios parciales previos, que se habian iniciado con textos tan clásicos, y sobre los que el autor volvería, como los referidos a la cúpula de Miguel Angel en la basílica de San Pedro o los de la biblioteca Laurenciana en Florencia. A partir de ellos Wittkower no sólo mostraba ya una inclinación preferente hacia temas arquitectónicos, sino que se introducía en una tradición de estudios hasta entonces detentados por maestros de la talla de Wölfflin, pero para aquilatar él ahora conceptos menos groseros en la valoración del arte italiano, distinguiendo fases y momentos como el de manierismo, "desconocidos" por el patrón conceptual del «clasicismo" que catalogaba a Miguel Angel directamente como "barroco". El texto de Wittkower arranca así de las tendencias antimanieristas de finales del siglo Xvi y alcanza hasta el momento neoclásico, por el que siempre manifestará su falta de interés, excepción hecha del luminoso artículo que dedica a la doctrina arquitectónica de Piranesi (1938-39).

Entre 1934 y 1956 se inscribe el llamado "periodo inglés» de Wittkower, huyendo del ambiente insoportable que introdujeron los nazis en la cultura centroeuropea. En su caso, además, venía a superponerse el significado de la patria paterna, pero como muchos otros intelectuales, A. Warburg el más significado y el catalizador de todos los estudiosos del arte, el cambio resultó proverbial para la cultura artística del país que generosamente les acogió, primero, adelanto de futuras famas añadidas, con el traslado de Warburg y su infinita biblioteca, núcleo de sucesivas ampliaciones y del centro de estudios más renombrado del panorama europeo de este género de estudios. Con Warburg y sus discipulos llega, a su vez, una tradición de estudios iconográficos, sello distintivo de las publicaciones de todos ellos y que tambien afecta a Wittkower, el cual habia conocido a Warburg en Italia, en 1927, y luego le había visitado en su biblioteca de Hamburgo previamente al definitivo encuentro londinense. El "Journal of the Warburg and Courtauld Institutes" será el soporte privilegiado en el que se escriban a partir de entonces los mejores textos en la materia, y sólo con verificar que la revista contaba en los años cuarenta con E. Wind, A. Blunt, T.S.R. Boase y R. Wittkower en su comité editorial puede permitirnos calibrar la fuerza y peso del empeño. Allí publica Witt- 
kower algunos textos ahora ya famosos, recupera viejas querencias hacia estudios simbólicos, de migración de los símbolos y de las formas, con especial hincapié hacia estudios relacionados entre oriente y occidente, tema que habia interesado siempre a algunos intelectuales germanos y ahora tambien a un Wittkower que se nos perfila en un ámbito próximo a los estudios del propio A. Warburg, F. Saxl, E. Gombrich y E. Panofsky, el resultado de lo cual quedará luego recogido en su obra póstuma "Alegoría y migración de los símbolos» (1989).

En el diario de Warburg publica Wittkower sus estudios sobre Alberti y Palladio, 1940-41 y 1944-45, base de la que será su obra principal, "Architectural Principles in the Age of Humanism» (1949), libro amplio, ambicioso y de largo alcance, que fue excelentemente recibido desde su aparición y sigue siendo un clásico permanentemente reeditado hasta la actualidad. Su primer generoso aval se lo dió el crítico e historiador K. Clark en la "Architectural Review", reconociéndole el mérito de haber eliminado lo puramente hedonístico y estetizante en la visión de la arquitectura del renacimiento, lo cual resultaba ser, leyéndolo en positivo, doble reconocimiento en la nación que había hecho suyas las lecturas al respecto de John Ruskin y Walter Pater. Con esta obra R. Wittkower trasciende, además, las tareas convencionales y el papel de un mero historiador de la arquitectura y se enfunda el ropaje de una "segunda" o, incluso, "tercera" histcriografía según la clasifiación de $H$. Sedlmayr, pues los planos del libro resultan poliédricos, conjuntándose la "deslumbrante y abrumadora erudición de los discípulos de Warburg ${ }^{3}$, con la novedad metodológica, el enfoque comprometido con el núcleo del discurso arquitectónico universal y no sólo con la evolución de sus formas o significados simbólicos y, finalmente, como colofón reconocido de la obra, se le suma su aportación e implicación comprometida en el debate arquitectónico contemporáneo. En este sentido, y como señala y estudia Alina G. Payne en su autorizada versión ${ }^{4}$, Wittkower consigue reunir dos intereses tradicionalmente separados, dándose continuidad a la arquitectura moderna y la lectura de la historia, escritura de la historia y crítica de la misma, ello ocurriendo en un momento histórico de debate y consolidación de ciertos estudios comprometidos defensores de la arquitectura moderna, como son las narracio-

Ángel Gonzalez: Prólogo a la edición en españo! del texto "Sobre la arquitectura en la edad del humanismo. Ensayos críticos”. Edit. G. Gili, Barcelona 1979.

Alina A. PAYNE: "Rudolf Wittkower and Architectural Principles in the Age of Modernism". JSAH. September 1994, págs. 322-342, Vol. 53. Véase tambien Branco MITRovic: "Objectively Speaking", en JSAH, March 1993, págs. 59-67, L. Il. Lionello PuPPI: «ll mutevole destino della pro porzione», en «Casabella», octubre de 1992, Vol. 56. 
nes de esa misma modernidad por parte de Nicolaus Pevsner y Sigfried Giedion.

Como señala Howard Hibbard ${ }^{5}$ en la "Nota Necrológica» escrita sobre la figura del que fue su maestro reconocido, lo que el libro de Wittkower significó fue un cambio radical en los estudios sobre el renacimiento, pero tambien además una nueva manera de ver, analizar y entender la arquitectura, camino hacia una valoración más objetiva de los estudios históricos, cifrando a éstos no sólo en interpretaciones formalistas o hedonistas, sino buscando, junto con lo anterior, el significado a partir de las valoraciones de los planos simbólicos, formales, tipológicos y "científicos», entendiendo por esto último las concomitancias históricas producidas entre las artes y las ciencias, en su caso concreto las matemáticas. Con anclajes en los estudios de E. Cassirer o de D. Frey, que ya habían emprendido el camino de descifrar las relaciones entre música y arquitectura a través de la proporción, Wittkower puede desplegar su tesis fundamental sobre las proporciones armónicas y la arquitectura del renacimiento, con las equivalencias ineludibles derivadas que llevan a utilizar conceptos como los de geometría ideal y forma simbólica, todo ello enfocado desde un plano estrictamente racional, buscando una explicación plausible al entendimiento — racionalizado- del deseo artístico, sin necesidad de caer por ello en las antirracionales teorías coetáneas sobre la sección aúrea y otros exoterismos

Palladio, como es bien sabido, es el soporte privilegiado de este discurso teórico trascendental de Wittkower, y una compañía ya permanente en los futuros estudios del autor. El propio arquitecto vicentino parecía haber vaticinado la necesidad de aunar arte y ciencia en su propia obra teórica y práctica, evitando reduccionismos.

No nos puede a partir de ahora resultar extraño o ajeno la permanente búsqueda de estructuras racionales en la historia, de estructuras primarias de base científica en épocas de embites al racionalismo arquitectónico, ni tampoco que defiendan con ansia manifiesta tales conceptos básicos y genéricos quienes, eran víctimas a su vez de la sinrazón nazi contemporánea. Pero, yendo más allá, o más dentro, del discurso histórico que propugna Wittkower, éste, en sus análisis arquitectónicos nos esta desvelando la necesidad de realizar análisis a partir de las formas, pero sin caer en el formalismo. Es más, hasta cierto punto, las formas añadidas, la ornamentación en la arquitectura, llegado un momento, dejan de

Howard HIBBARD: «Rudolf Wittkower (1901-1971). An Obituary», en "The Burlington Magazine», n."114, March 1972, págs. 173-177. 
interesarle, incluso le estorban al autor en sus análisis históricos valorativos: no es un principio fundamental y más bien pertenece a la forma escultural, por tanto a la sobreposición ideológica sobre lo arquitectónico.

La pregunta histórica y contemporánea era, pues, la necesidad de recuperar y establecer modos de control y de sistematización normativa de manera de poder sustraer al proyecto de arquitectura de su carga de subjetividad. Las proporciones, aceptadas, servian mejor que ninguna otra posibilidad para fijar dichos principios de objetividad, aunque luego acaben sirviendo sobre todo a dar fama a los un poco menos racionales del «modulor" lecorbusieriano. Pero el trabajo del historiador comprometido y discreto, si está correctamente ejercitado, desvela la «necesidad» de hablar de la historia desde el presente, y viceversa, como un fin último inherente a su figura y trabajo, valoración que siempre acompañará a la conciencia del autor, de R. Wittkower, y así nos lo hace notar en el «Prólogo" de su obra más tardía "La escultura. Procesos y principios", editada por Margot Wittkower en 1977, dado que sus propósitos consistían en "ofrecerles unas cuantas interpretaciones serias e históricamente válidas, incluso sobre la época moderna, ya que mis criterios se derivarán siempre de hechos atestiguados por varios milenios de historia (...), confío así poder exponerles algunas conclusiones sacadas de unas realidades observables $\mathrm{e}$ incontestables (...), al estudiar los métodos de trabajo de los escultores pretendo descubrir sus ideas y convicciones artísticas" (de la edición española, Alianza Edit., Madrid 1980).

¿Un Wittkower antihedonístico? Sí, al menos partiendo de la tradición inglesa hasta entonces satisfecha con la lectura subjetivista de J. Ruskin, W. Pater o G. Scott, cada uno de ellos defendiendo un sentido inmanente del arte, de las obras de éste autojustificadas y exentas de cualquier "responsabilidad civil» con su época, procurando sólo la emoción estética, el principio del placer, su oferta sobre el observador.

Lo científico del modo de actuar de Wittkower, su implicación contemporánea interesada, el entendimiento de la arquitectura como un modelo humanizado del mundo, presupone la cortapisa principal al hedonismo que se había impuesto en la cultura inglesa, en particular en lo referente a los estudios sobre el renacimiento italiano, ello hasta las últimas consecuencias, normalmente consumadas en los literarios y a veces sublimes viajes a Italia emprendidos bajo los auspicios y los efectos deseados por L. Sterne, que los había inaugurado con el explícito título de «viaje sentimental». Antihedonismo, pues, y tambien, en lo que dichas posturas mantenidas proclaman de ahistórico en sus valoraciones, sensibilidad y análisis que Wittkower defiende con ahínco estructural, anteponiendo dicho argumento 
a la privilegiada relación sujeto/objeto, o lo que es lo mismo, la pervivencia, ahora ya sí definitivamente superada, de la teoría de la "einfühlung" y de la "kunstwollen" de Wölfflin, Riegl y Worringer ${ }^{6}$.

En esta estela de reacciones, el propio E. Gombrich lo hace con algo de contenida virulencia en la "Introducción" de su célebre texto "Arte e llusión", en concreto contra la negación contemporánea del análisis causal de la historia, que él ejemplifica en el caso radicalizado de $\mathrm{H}$. Sedlmayr, "que concibe el cambio histórico como resultado de cadenas de causación ciegas y aisladas". Los análisis arquitectónicos de R. Wittkower, con tantos débitos y relaciones próximas (los citados D. Frey, P. Frankl, S. Giedion...) reduciéndose a valores documentales y a análisis formales sintácticos, observando la arquitectura desde la planta, el alzado y no sólo desde la visión ornamentada exterior, causa finalmente el "placer» de toda construcción mental en la que se logra hacer coincidir de manera verosímil el humanismo y la explicación racional, en su caso de cariz geométricomatemático, de las obras, un puente que se lanza, pues, entre el humanismo y la abstración. Al mismo tiempo, sin perder de vista la acción creativa del artista, bajo ese afán suyo de valorar la importancia dada, y que se mantendrá, a la «biografía» como auténtico género, pero que, más que disculpa $u$ homenaje pseudovasariano, reivindica la acción activa del artista, desconsiderando, por el contrario, cualquier valoración de éste como sujeto pasivo a través del cual se viniera a manifestar el lábil principio del deseo y del placer a lo largo de la historia.

Los citados Alina A. Payne y L. Puppi se han interesado en sus respectivos comentarios anteriormente reseñados por la recepción de las ideas de R. Wittkower, encontrándose su eco, por ejemplo, en los textos de $C$. Rowe y la aplicación de las matemáticas al estudio de la villa ideal, en enfoques de revistas como "Casabella", "Dedalus", en el entorno editorial de N. Pevsner... La lectura de C. Rowe sobre Le Corbusier, las estrategias compositivas de este último, y las retóricas del propio Rowe, relacionando la villa Malcontenta con la Stein, avalan la propia tesis defendida por R. Wittkower a propósito de la relevancia del pasado para explicar el presente. La erudición histórica de $\mathrm{R}$. Wittkower, esa a la que A. González aludía en defensa de «la lucidez de Wittkower hurtándose al círculo vicioso de la "eruditio" descarnada, para suscitar nuevos problemas historiográficos y encaminarlos documental y críticamente", sirven como soporte para alcanzar metas más elevadas, que aluden al núcleo más ín-

6Udo KultermanN: “Historia de la Historia del Arte. El camino de una ciencia». Edit. Akal, Madrid 1996. 
timo de la cultura arquitectónica y artística: la búsqueda de un orden, y la pervivencia del clasicismo, pero más en términos conceptuales y abstractos que estrictamenten formales. Dicho con otras palabras, el propio Wittkower lo resumía en una comunicación titulada "History as Discipline", enviada al Congreso de 1959 en Winterthur: "(La historia del arte) es sobre todo en primer lugar la historia de los artistas y de los estilos, de los temas (esto es, de la iconografía) y de las técnicas; y la historia de las ideas y de las concepciones subordinadas a la obra de arte" ${ }^{7}$.

Mensaje lanzado desde la lectura del pasado, producto de la reflexión a la que ha conducido el camino metodológico precedente, y ejemplo que desde la historia se concluye a manera de estímulo verificado en el tiempo pretérito que invita a considerar «la necesidad de recuperar o establecer en la actualidad modos de control o de sistematización normativa de las proporciones, con lo cual se podría fundar la "bondad» del proyecto sustrayéndola de la arbitrariedad" ${ }^{8}$. Tareas de los arquitectos del renacimiento, logros consecutivos, pero tareas del arquitecto contemporáneo, no a través de la incitación programática del texto de Wittkower, sino sitas detrás de su lectura, de la erudición documental y bibliográfica incluso. Finalmente, reivindicación de los vaiores de los edificios, que son portadores de las aspiraciones de sus trazadores responsables.

Palladio resulta un caso ejemplarizante como pocos, además de un filón inagotable en los estudios de R. Wittkower, tanto en su dimensión biográfica puramene italiana, como en su proyección inglesa posterior, asuntos estos últimos finalmente recogidos en el texto "Palladio and English Palladianism". A partir de la figura de Palladio, el sofisticado entramado de las proporciones armónicas abre su amplio espectro de posibilidades, la geometría pasa a ser el argumento articulador del discurso y un arma difícil de rebatir que acude en ayuda de las interpretaciones del autor, como ocurre, por ejemplo, cuando finalmente ya seamos incapaces de entender la "escenografía" de la iglesia veneciana del Redentor si no es a partir de las ideas adquiridas en el texto correspondiente de R. Wittkower.

La «migración» del palladianismo a Inglaterra podría parangonarse como un paralelo específico de otras grandes trashumancias históricas, presentes como temas en otros estudios del autor, y en el interés general del circulo vienés, con el añadido del "toque nacionalista» que la importación de la arquitectura palladiana comportó - las vicisitudes de los

\footnotetext{
Citado por L. PuPPI, "Casabella», 1992.
}

Ibidem. 


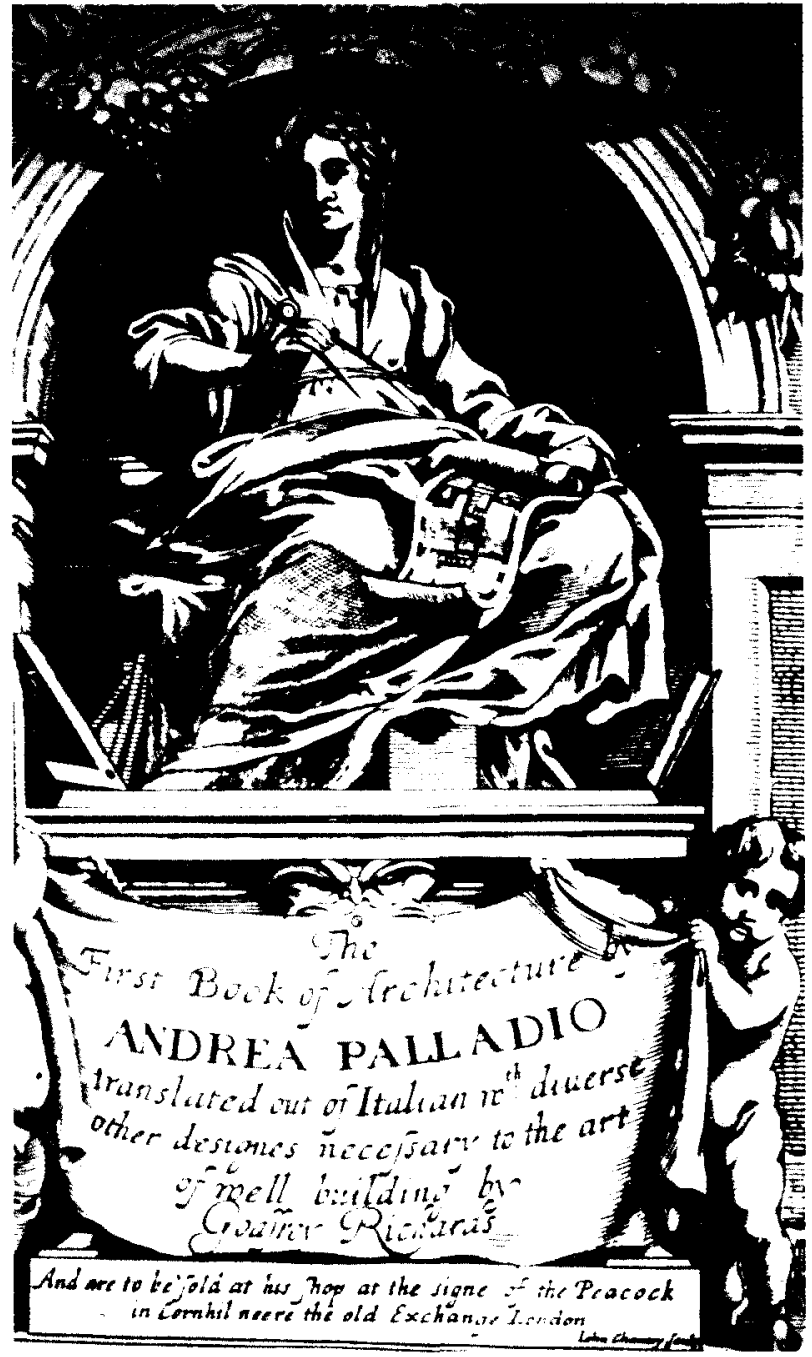

Fig. 1. Godfrey Richards. Frontispicio del libro "The First Book of Architecture by Andrea Palladio», 1663, primera traslación al inglés de los "Quattro Libri».

"Quattro Libri», o los elementos pseudopalladianos en la arquitectura inglesa- que podría ser tomado como un rasgo positivo, como una reivindicación indirecta del pasado desde el presente, respaldando la necesidad de todo presente de apropiarse de los temas añadiendo dosis de subjetividad (nacional) con relación a la forma y significado de los mode- 
los adquiridos, al igual que lo había efectuado el palladianismo inglés con respecto a las fuentes y motivos renacentistas italianos. Dicho camino, de la apropiación a la liberación creativa de los temas palladianos, se recorre de la mano sucesiva de Inigo Jones, Lord Burlington y William Kent, cada uno de ellos viajando a Italia, primera causa directa, pues, de la «migración" posterior de las formas, estructuras y arquitecturas comprendidas y asumidas desde la interpretación racional, desde el estudio profundo de su conmensurabilidad y verificación empírica, como ya ocurría con las acotaciones de Inigo Jones en las páginas de su ejemplar de los "Quattro Libri» confrontando las figuras del mismo con la realidad construída. Así, la personalidad de Jones, preludio de la reacción clásica dieciochesca, queda perfiladada por $\mathrm{R}$. Wittkower según cuatro rasgos fundamentales y definitorios: asunción del ideal renacentista de universalidad, saber específico alcanzado mediante el estudio, base filosófica como punto de partida de una teoría que considerando la concepción platónica de una armonía universal fundamentada en los números confirmase el hecho de que la arquitectura para Jones "era, en primer lugar, y sobre todo, el arte de las relaciones métricas en el espacio" - «Inigo Jones, arquitecto y literato", 1953-, tesis que derivaba de las concepciones sobre la interpretación racional y matemática de la belleza, sobre la convicción del valor universal del número que $\mathrm{R}$. Wittkower había expuesto en los estudios "palladianos" de "Architectural Principles in the Age of Humanism» cuatro años antes.

Aunque el neoclasicismo gozó de su falta de interés, y así lo manifestaba el autor a la hora de justificar las categorias y periodizaciones utilizadas en el texto "Arte y Arquitectura en Italia, 1600-1750» -1958-, se ve abocado a exumar tan contumaz acepción estilística para definir mejor el movimiento de reforma de las artes en Inglaterra durante la primera mitad del siglo XVIII - «El Neoclasicismo inglés y los Qattro Libri de Palladio»-, de manera que $R$. Wittkower contribuye a enfocar una lectura amplia, universalista, del concepto "neoclasicismo", en el que prima más el peso de la interpretación continuada implícita en el término "clasicismo" que la aceptación espacio-temporal convencionalizada del "estilo neoclásico». En este texto, lo mismo que en "La literatura inglesa sobre arquitectura", ambos en forma original de conferencia y sólo publicados en el soporte de libro en "Palladio and English Palladianism», el juego de "migraciones" propuesto por $\mathrm{R}$. Wittkower resulta apasionante, una invitación general a considerar la historia del arte como una relación de influencias, aceptaciones e interpretaciones de formas y modelos culturales, una dialéctica itinerante del arte efectuada en varios planos complementarios de artistas -Bernini en París-, de viajes de estudio - Inigo Jones en Italia-, de 


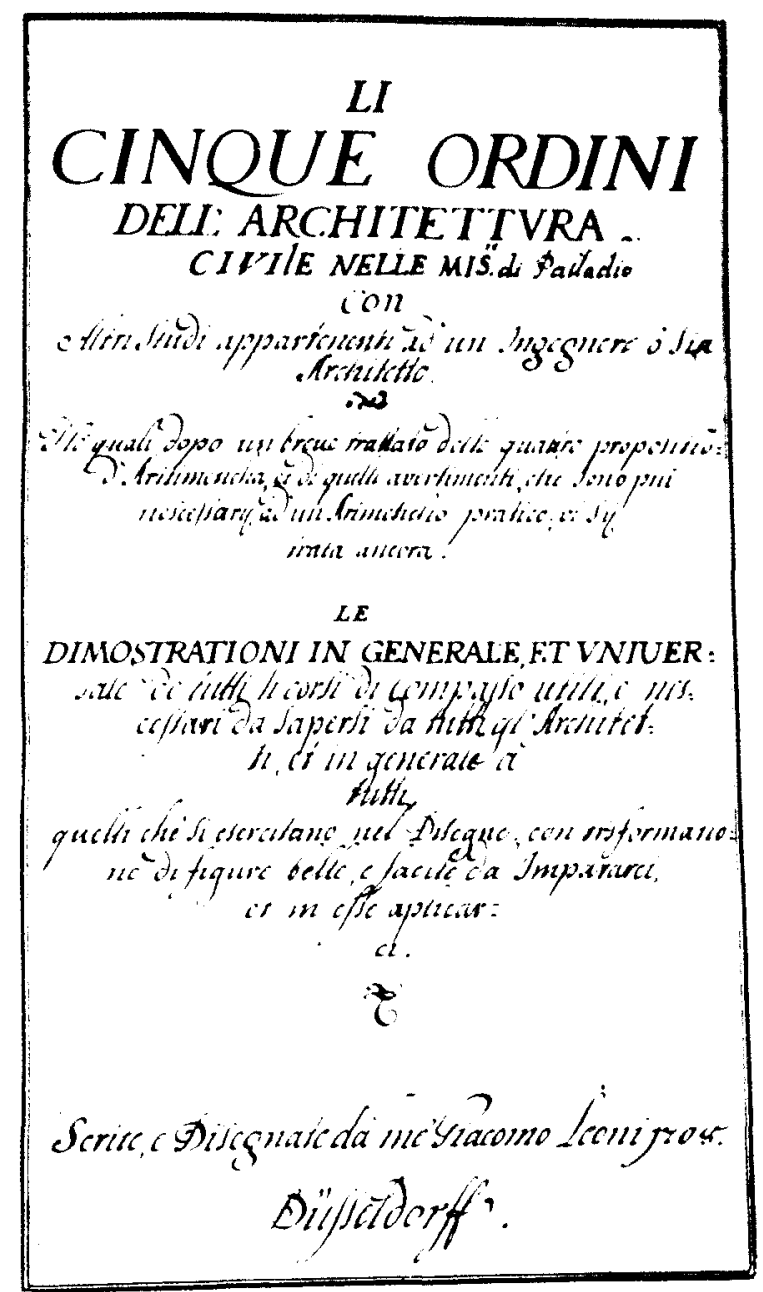

Fig. 2. Giacomo Leoni. "Li Cinque Ordini dell'Architettura" 1708.

publicaciones textuales, de ideas universales válidas, como las de la razón y su belleza debida, en definitiva.

Esto no era tampoco novedad en R. Wittkower, sino el fruto aplicado de anteriores exitosas tareas, en concreto la exposición y libro "British Art and the Mediterranean", trabajo conjunto con Fritz Saxl, (1948). La agilidad practicada por $\mathrm{R}$. Wittkower para desvelar tantos nexos entre el genio 


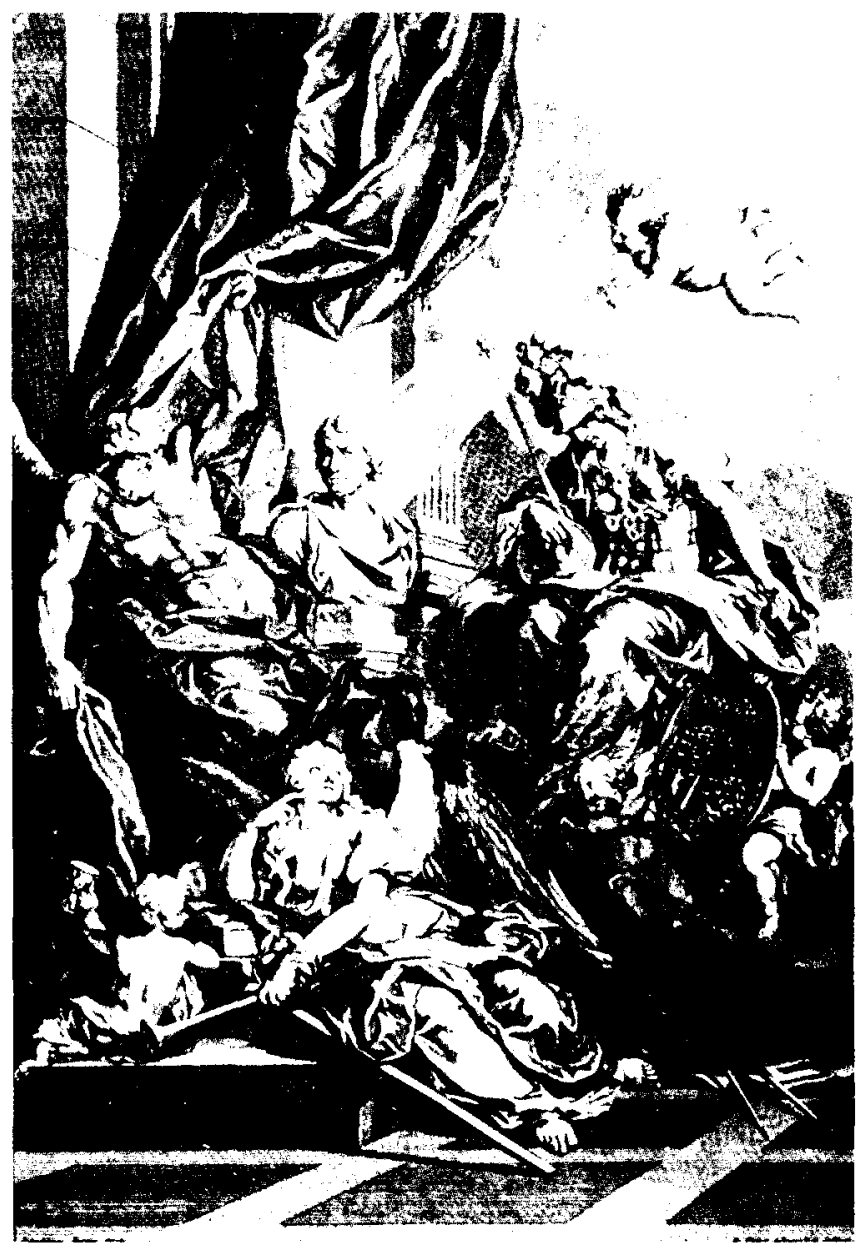

Fig. 3. Giacomo Leoni. Fronstispicio de la traslación al inglés de Palladio. 1716.

de Italia y el que comienza a prender a través suyo en Inglaterra, la movilidad espacio-temporal de sus disquisiciones consiguen, en doble valoración, justificar a través de la bondad del texto la de la propia cultura inglesa estudiada y dejar expedito el camino, que es estela por la que acabarán navegando y explicándose mejor las aportaciones no menos brillantes de P.Collins, J. Rykwert o R. Tavernor, todos aceptando ya el neopalladianismo como la primera fase del neoclasicismo inglés, y la idea de que en éste se verifica la más importante revolución del pensamiento moderno sobre arquitectura. Así, con doble valor, retrospectivo y de proyección en 


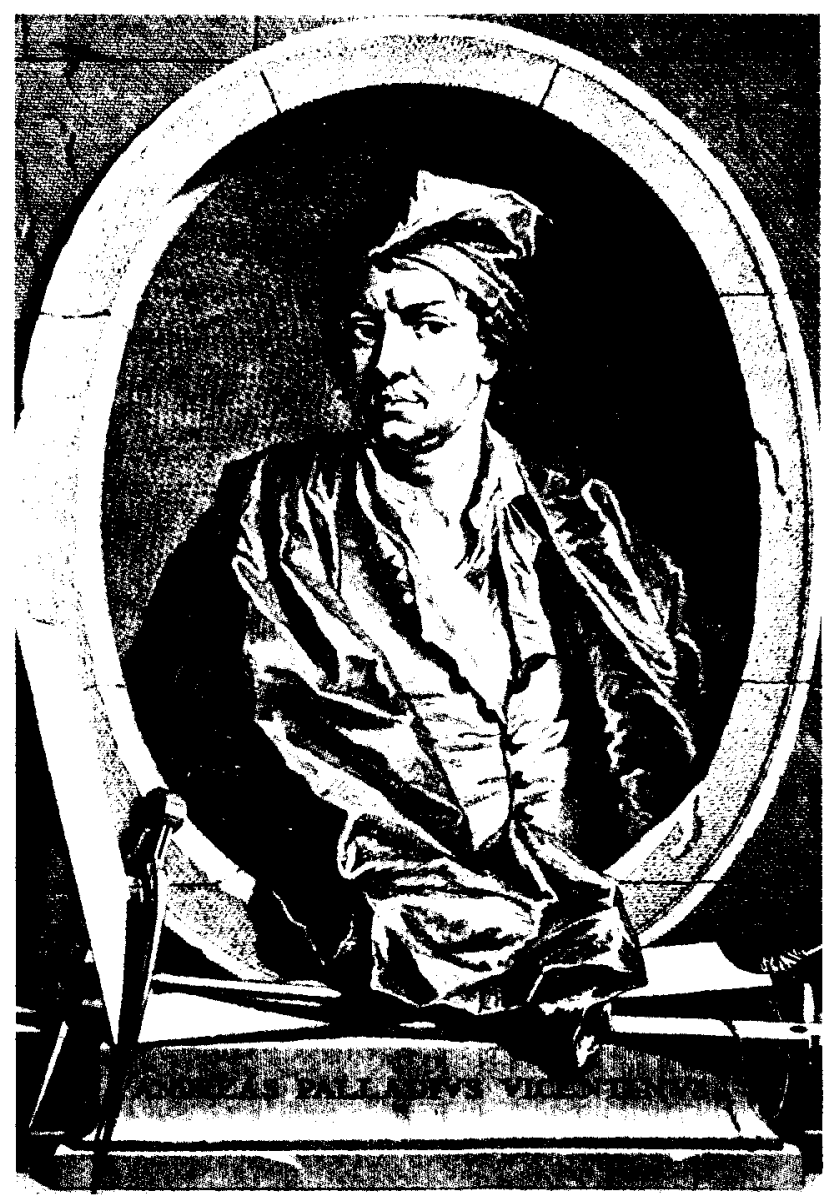

Fig. 4. Giacomo Leoni. Retrato, apócrifo, de Palladio publicado por Leoni en 1716.

el porvenir, el «neopalladianismo» se llena de contenidos imprevistos, se carga de significados diferenciados hasta constituirse él mismo en una entidad, en una manifestación específica no exenta de connotaciones "nacionales" modernas y con larga progenitura en el tiempo porvenir. La fortuna del clasicismo resultó así estar mejor salvaguardada en la Inglaterra dieciochesca que en ningún otro solar continental, y sus visos son de inagotable riqueza, que ahora se exploran con fuerza optimista y ampliación de repertorios agotados en otros contextos, como lo es en su aplicación al terreno del jardín, — «El Neopalladianismo inglés, el jardín paisajístico, China y la llustración»-, de 1965. 


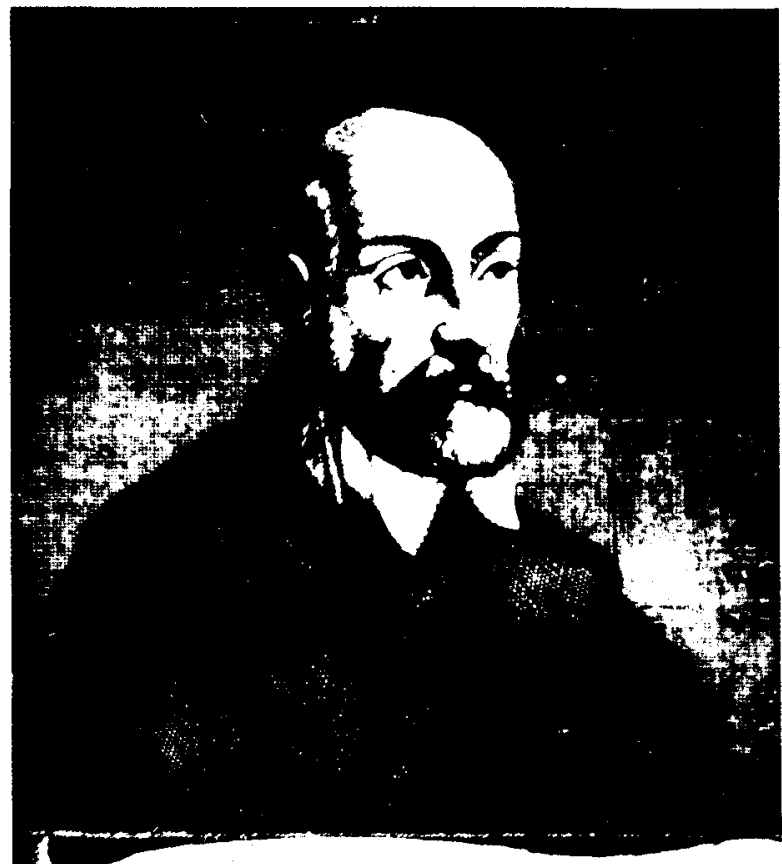

ANDREAS PALLADIVS ex elggande cuntiqua tabella apud Marth Capra Bicicias Vicetinos

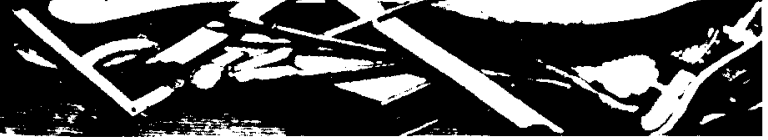

Fig. 5. Retrato real de Palladio, grabado por Zucchi.

En su madurez, R. Wittkower se enfrenta al combate pospuesto con el neoclasicismo, indaga en busca de un nuevo orden dentro de un tiempo, el siglo Dieciocho, que él no duda en calificar como carente de una fisonomía estilística coherente, más bien tendente a un caos estilístico en parte exorcizado en Inglaterra por las benéficas ataduras del neopalladianismo. Como un rescoldo de explicación winckelmanniana, R. Wittkower atribuye el éxito de la síntesis histórica insular a lo que denomina el triunfo de un "clasicismo democrático» con el que «la arquitectura clásica y el jardín paisajístico resultan ser dos aspectos ligados entre sí a un renacimiento artístico que era el producto y al mismo tiempo la expresión del bienestar de una sociedad libre". Pero fiel a su figura y a sus convic- 


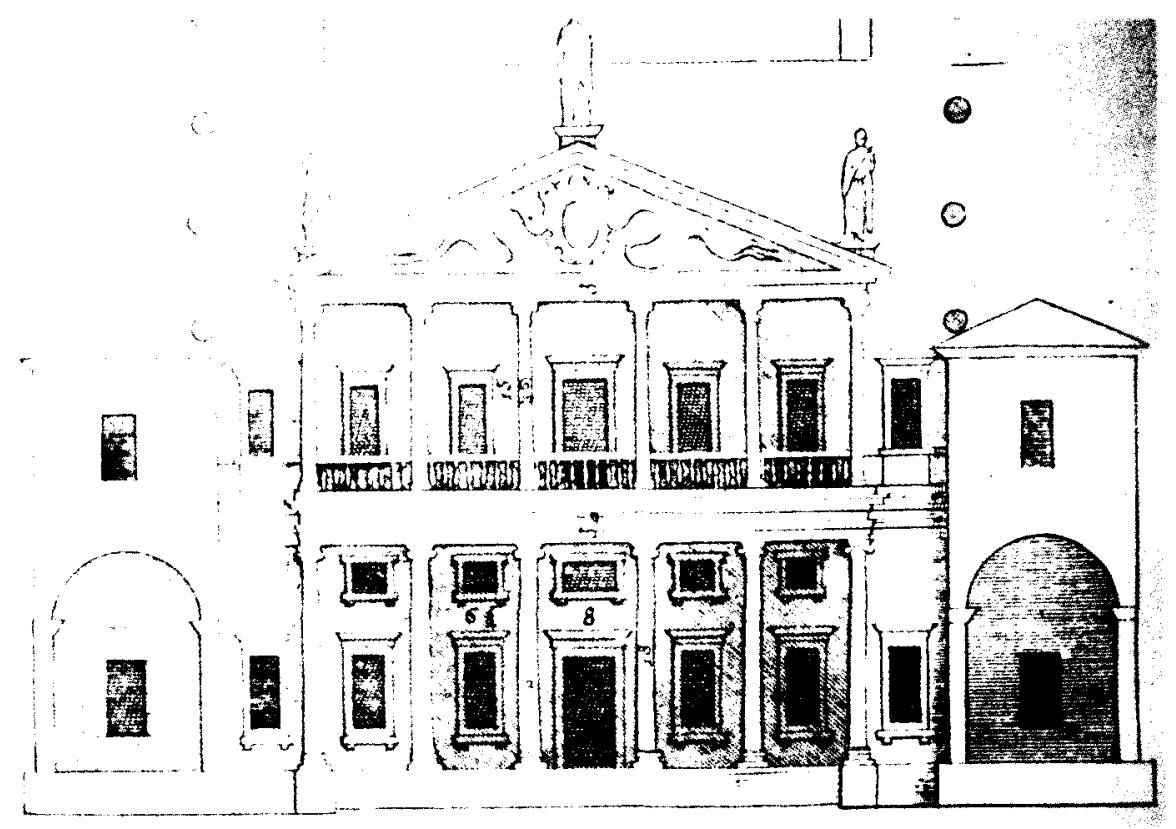

Fig. 6. Palladio. Villa Valmarana, de los "Quattro Libri", 1570.

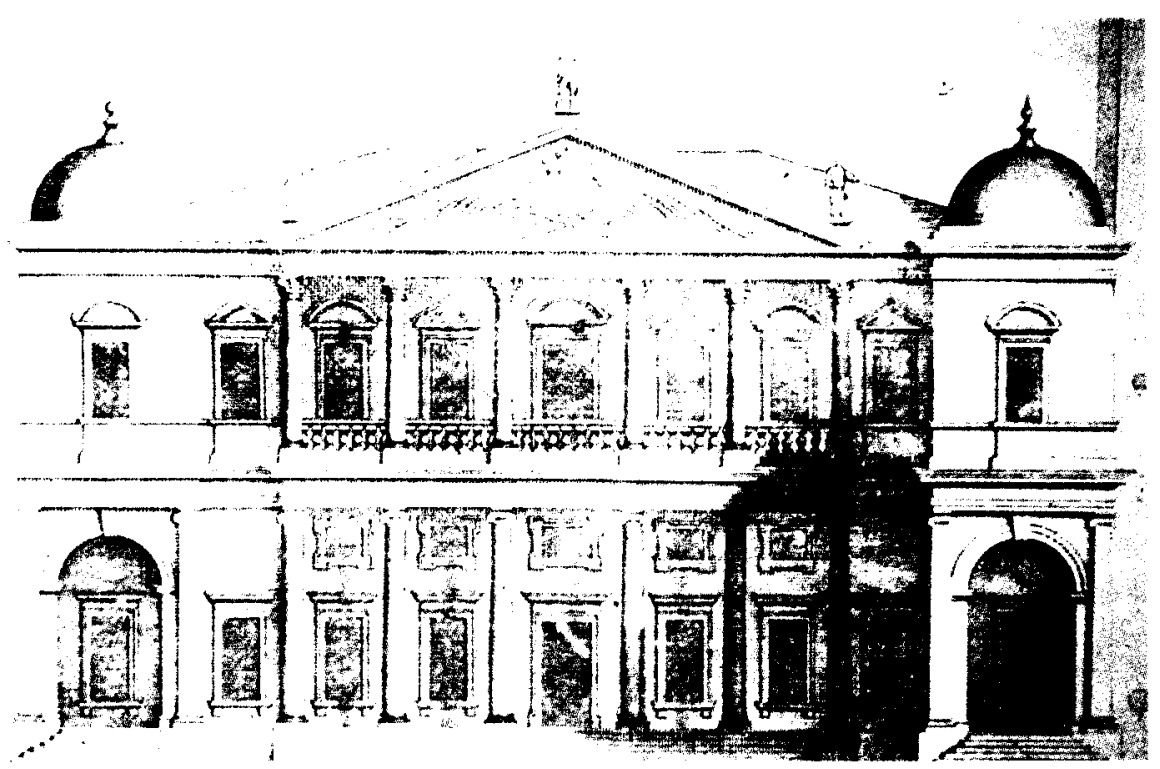

Fig. 7. Giacomo Leoni. Villa Valmarana, según la edición de 1716. 
ciones intimas, a sus preferencias biográficas, R. Wittkower interpreta finalmente la nueva sensibilidad del Setecientos sin necesidad de llevar sus valoraciones más innovadoras a un adelantamiento histórico del pensamiento romántico, sino que pesa en él la formación clásica: "todos estos escritores enfrentaban el problema de la sensibilidad con las armas del racionalismo heredado del Seiscientos» - "Teoría clásica y sensibilidad en el Setecientos"-.

\title{
Andrea Palladio's Five Orders
}

O F

\section{ARCHITECTURE.}

\author{
IV I T H
}

His Treatifes of Pedeftals, Galleries, Entries, Halls, Roons, Floors, Pavenems, Cilings ; various Arcises, Gates, Doors, Windows, Clommies, Siaur-Cafes, and Roofs.

Together with

His Oblervations and Preparations for

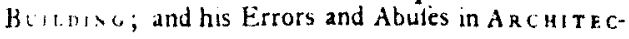
TURE.

Fithlully Tramated, and all the PI. A tes cxatty copied from he Firfl Italian Edition printed in Venice is 70.

Revifed by

COLEN CAMPBELL, Efq; Author of Vitruvius Britannicus.

To which are added,

Five Curious $\mathrm{P}_{\text {r. A t }}$ s of Doors, Windows, and CbimncyPreces, invented by Mr. Campbell.

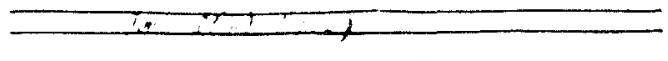

$L O N D O N$

Printed for S.HARDING, at the Bible and Anchor on the Pavement in St. Martins-Lane MDCCXXIX.

Fig. 8. Colin Campbell. Edición del texto de Palladio, 1729. 


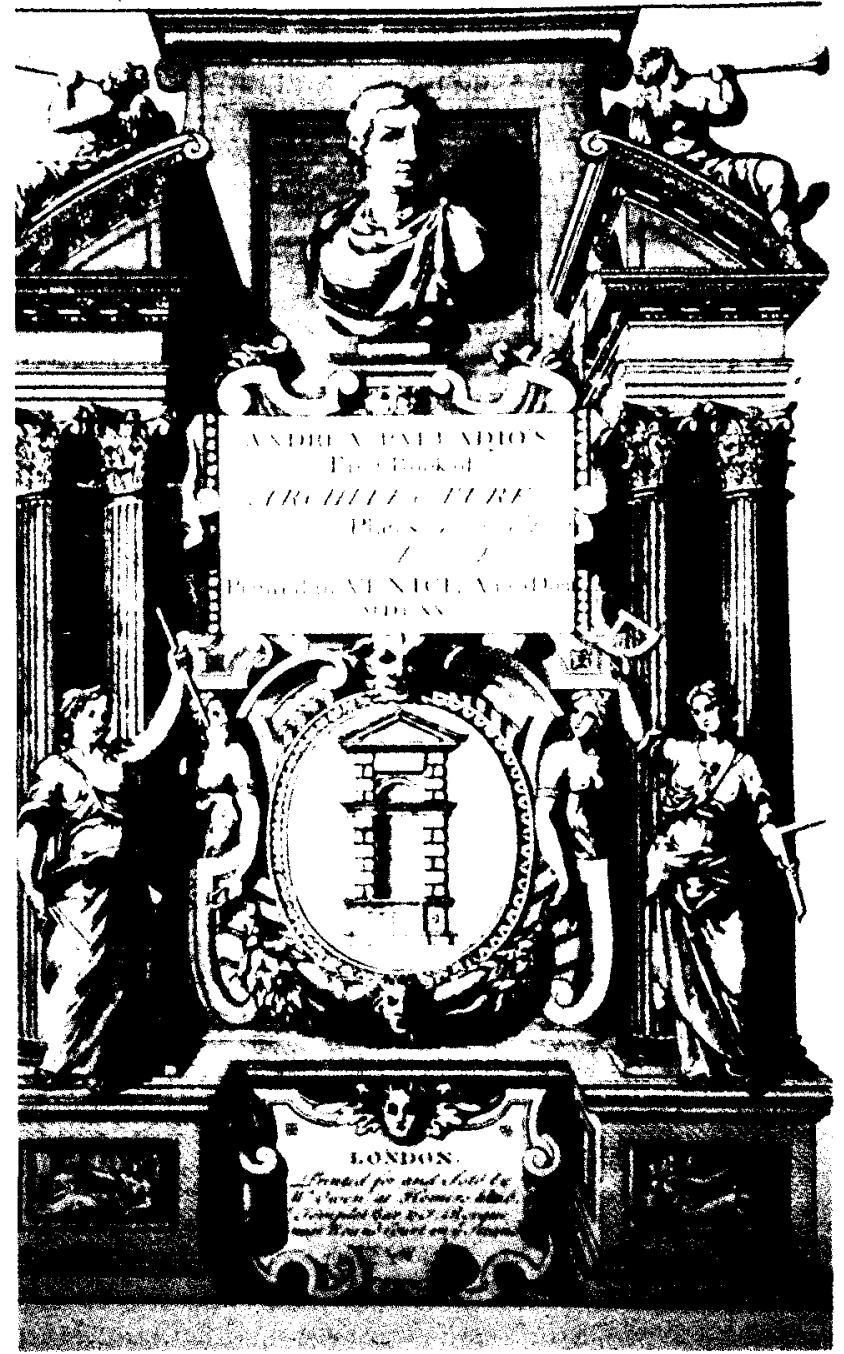

Fig. 9. Hopus y Cole. Frontispicio del "Andrea Palladio's Architecture», 1733.

A partir de 1956 R. Wittkower se incorpora a la Columbia University de Nueva York, y en ella permanece hasta su jubilacion, en 1969, aunque siguió siendo profesor a tiempo parcial en la Slade School of Art del University College de Londres, de manera que el vínculo inglés no se desvaneció nunca del todo, aunque el verdadero florecimiento de su carrera va 


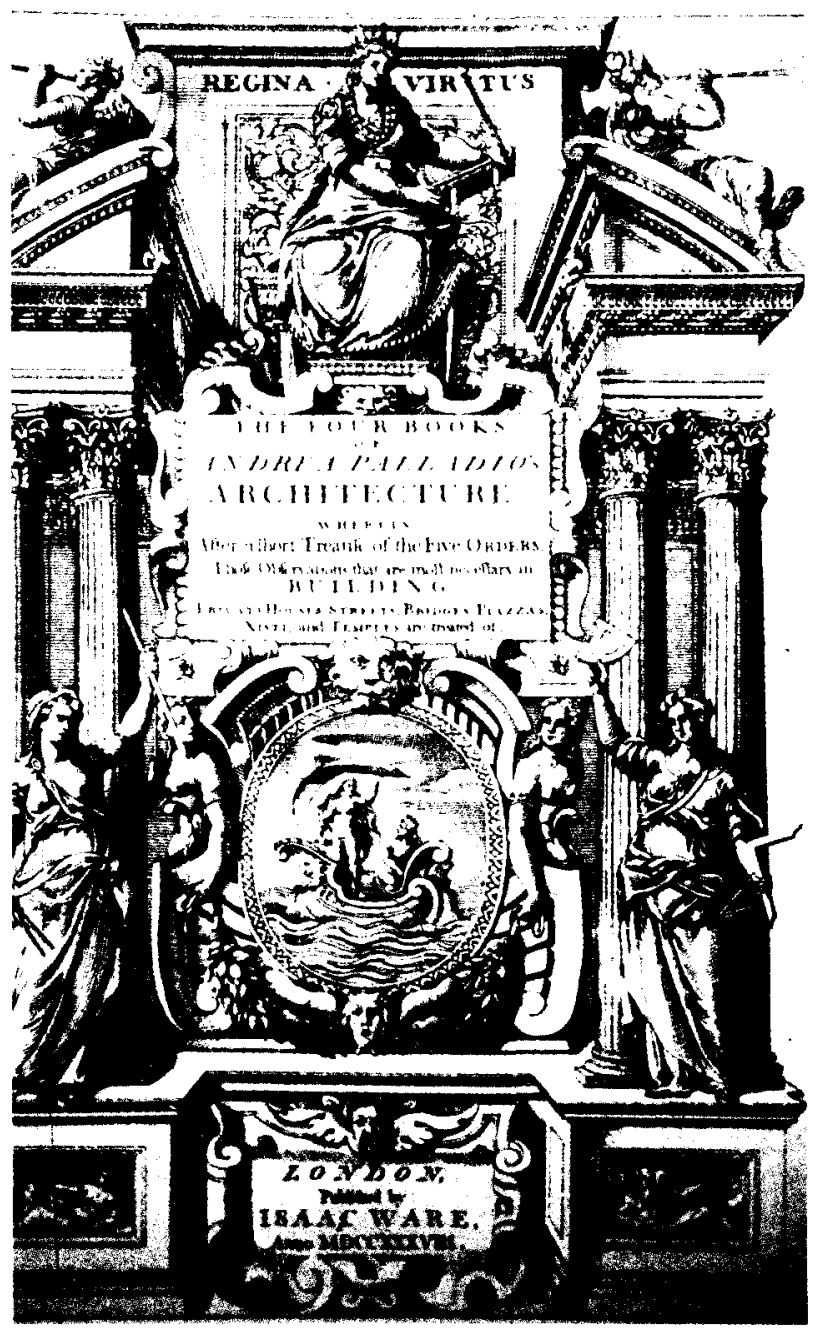

Fig. 10. Isaac Ware. Edición del Palladio, 1738.

unido a su adscripción a la universidad americana ${ }^{9}$. Los libros más divulgados del autor pertenencen a este período: "Arte y Arquitectura en Italia,

R. RuBINSTEIN, dei Warburg institute, a quien debemos preciosas informaciones directas sobre R. WITTKOWER, ello a través de la investigadora del CSIC, Gloria MORA, a quien mostramos 
1600-1750" - 1958- y "Nacidos bajo el signo de Saturno" - 1963-, además de otros que cierran su ciclo en torno a la figura de Miguel Angel: "The Divine Michelangelo» y «La cupola di San Pietro di Michelangelo", ambos de 1964.

El destino americano de tantos intelectuales europeos se acaba cumpliendo tambien en R. Wittkower, un eterno vagar el suyo hasta este último aposento, con medios a su disposición para abarcar tanto las tareas de investigación individual como las organizativas del Departamento de Arte y Arqueología, y así se le recibe como autoridad y dispuestos a aprovechar y potenciar las condiciones y experiencias excepcionales del sabio berli-

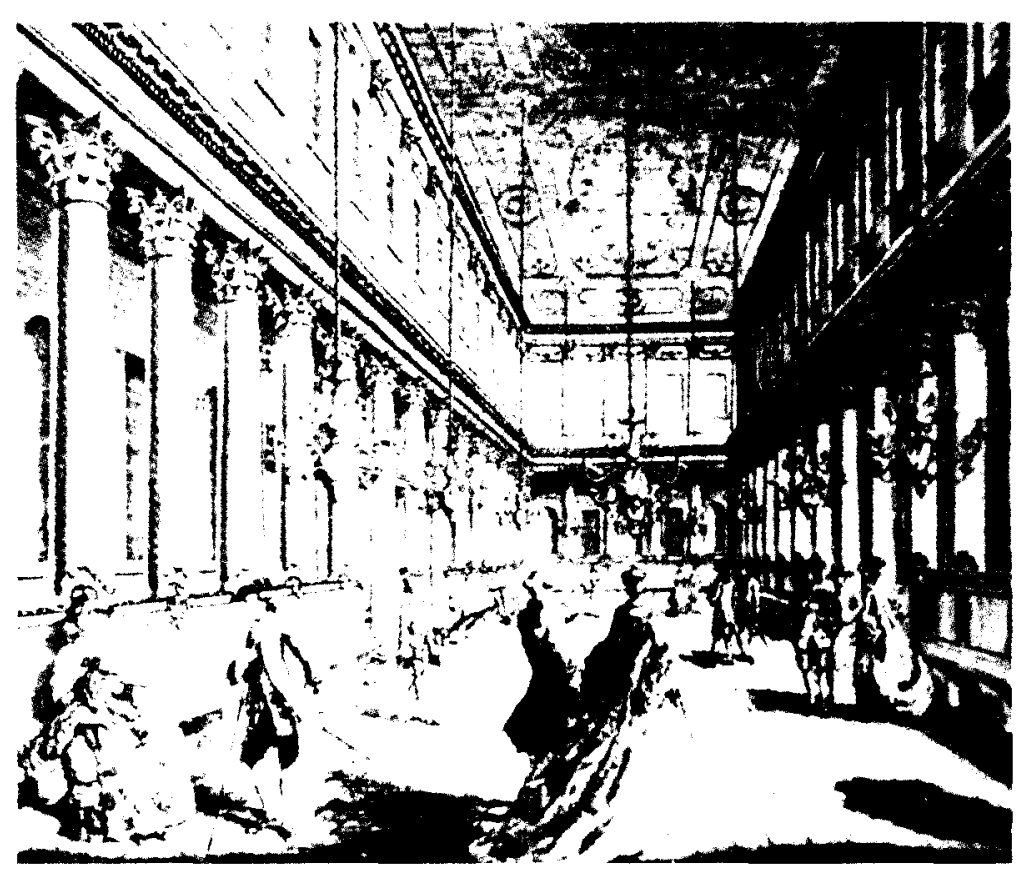

Fig. 11. Lord Burlington (autor). Grabado de la Assembly Rooms de York con el aspecto, alterado, correspondiente a 1859.

el más sincero y merecido reconocimiento. R. RUBINSTEIN fue en pos de R. WiTTKOWER a Inglaterra en 1949 para pedirle ser el director de su tesis, y alli se quedó para siempre. R. RUBBINSTEIN compartió amistad con los WITTKOWER, que en los dias de 1949, entre septiembre y diciembre, la aco gieron incluso como huésped de pago, y aún hoy en dia para ella los WITTKOWER "remained the wisest, sanest and most stimulating of friends". Margot WITTKOWER, fiel colaboradora primero, y mantenedora después de la obra de su marido, falleció en julio de 1994 


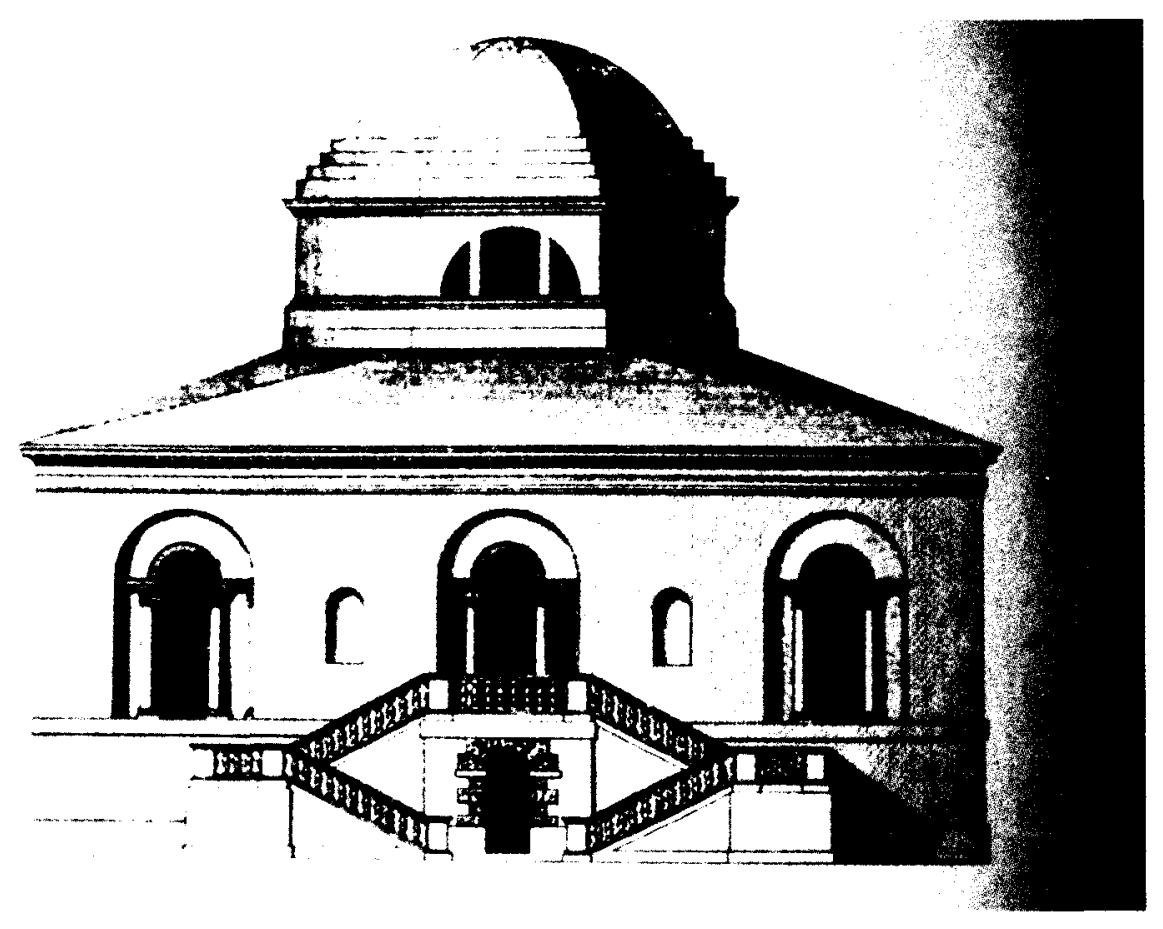

Fig. 12. William Kent. Fachada al jardin de la Chiswick House, 1727.

nés. Los testigos y biógrafos de esta etapa de R. Wittkower ${ }^{10}$ coinciden en resaltar la importancia de su tarea docente y la fuerza con la que respondió al desafío: creación de seminarios en colaboración con museos y coleccionistas en pro del trabajo de sus estudiantes, consecución de fondos que posibilitasen a éstos viajar y conocer «in situ" los lugares y las obras, recomendándoles luego incluso la mejor manera de "ver». En Venecia,

10 Howard HiBBARD: «Rudolf Wittkower (1901-1971). An Obituary". The Buriington Magazine n. 114, March 1972, págs. 173-177.

R. Witrkower había estado en Harvard entre 1954 y 1955 , siendo entonces H. HibBard estudiante. En la citada "Necrológica", Hibbard reconoce la influencia recibida en etapa tan juvenil, y en particular resalta las virtudes de la seriedad, erudición y entusiasmo como aspectos que le quedaron grabados de la personalidad de R. WITTKOWER.

Véase también David ROSAND: "Rudolf Wittkower. 1901-1971", en "Proceedings of the British Academy", n. 90, 1996. págs. 575.589.

NOTA FINAL: Las ilustraciones de los grabados que acompañan a este texto son parte de las que to hacian a la edición original en inglés del de R. Wittkower "Palladio and Palladianism" (1974). 


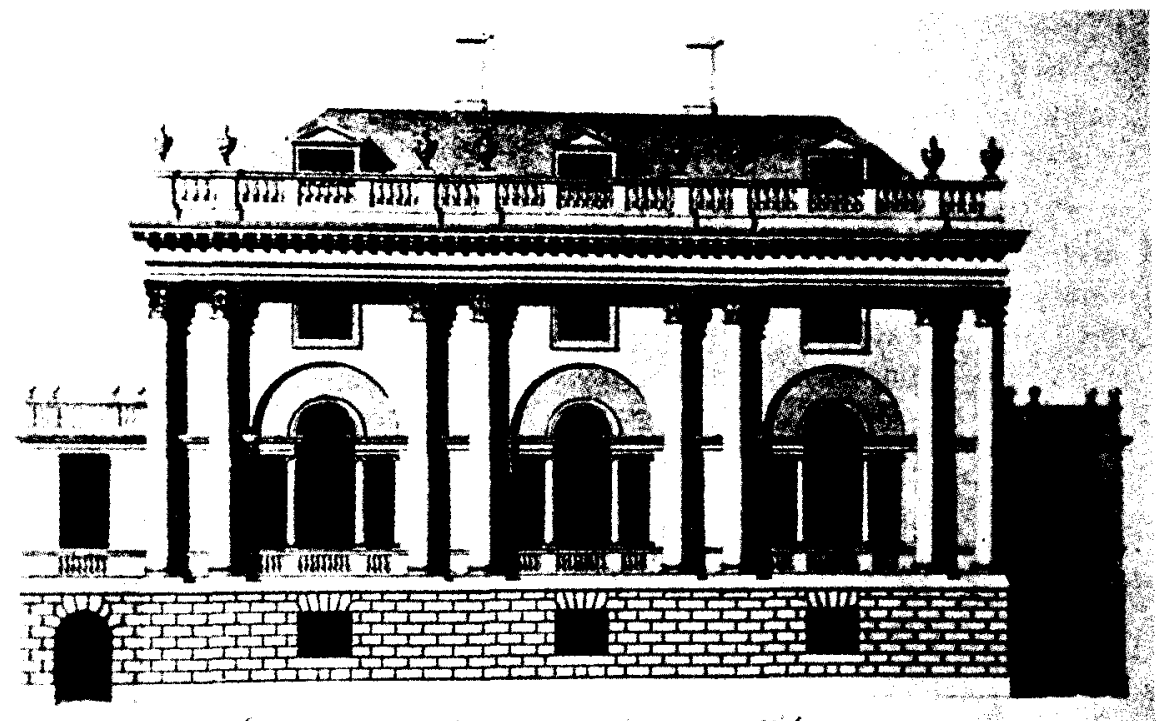

Fig. 13. James Paine. Sir Matthew Featherstonehaugh's house, 1755, según su publicación «Plans, Elevations, Sections" (1783).

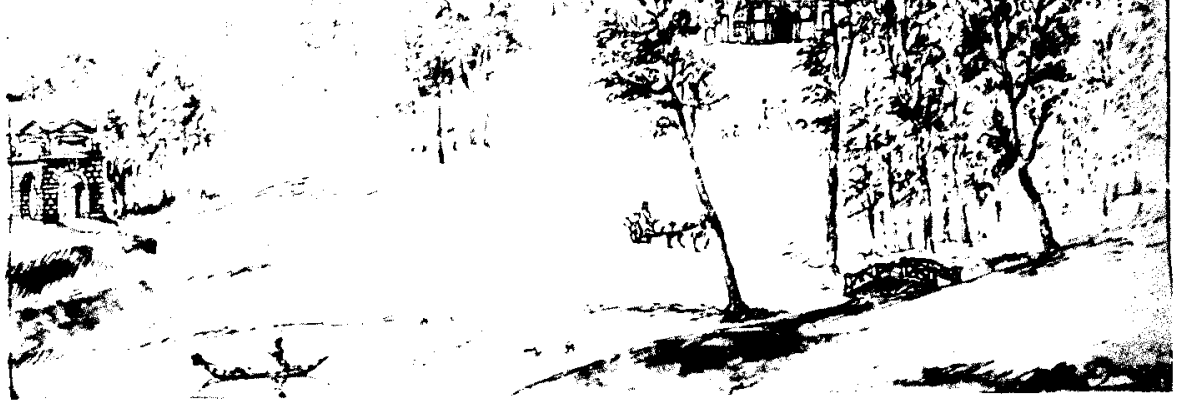

Fig. 14. William Kent. Diseño para los jardines de la Holkham Hall, 1734. 
por ejemplo, lo ideal era madrugar y ver la ciudad con la luz de las primeras horas del día, y leer y escribir por la tarde.

El único fiasco, el último desencuentro fue de nuevo con un erudito alemán hijo del mismo exilio, R. Krautheimer, del Institute of Fine Arts de Nueva York, no menos entusiasta y persuasivo, con parecidos intereses y una misma pasión compartida por Roma, por la ciudad, por la Biblioteca Hertziana. R. Krautheimer, longevo como pocos - había nacido en 1897tuvo el raro privilegio, siendo ya nonagenario, de vivir durante las estancias romanas en un piso alto de la propia Biblioteca Hertziana, desde donde, único superviviente de una generación fantástica de historiadores centroeuropeos, podía contemplar, ya sólo definitivamente, hermosas puestas de sol sobre la ciudad que todos habían querido interpretar y conocer lo mejor y más felizmente posible. 
